\title{
Psychiatry at the end of the 20th century
}

\author{
H Heimann
}

Goethestrasse 23, 7400 Tübingen, Germany

\begin{abstract}
Summary - The political role psychiatry plays in mental health strategies in the 20th century is discussed as well as the dangers of abuse when totalitarian ideologies rule supreme. The author comments on positive developments in the sectors of applied psychiatry and psychotherapy after World War II and the implementation of uniform requirements for the classification of psychopathological disorders as well as their limitations. Psychiatry as a scientific discipline relies on two fundaments: the conclusions drawn from the collective, present and past experience of psychiatric medicine and the impulses given by neighbouring disciplines such as neurobiology, psychology and sociology. These influences are necessary for the advancement of psychiatry, but can be restrictive in that they lead to tunnel vision by giving simple explanations for mental disorders of complex or unknown etiology. A multidimensional approach is required for the elaboration of adequate therapies and research must avoid dogmatism and short-sightedness.
\end{abstract}

mental health politics / history of psychiatry / nosology

An objective survey of psychiatry is always limited by the personal experience of its surveyor. Thus, the present elaborations have not only been influenced by Swiss and German psychiatry, the countries of my mental and vocational origin, but also by the European psychiatric community. The European Association of Psychiatrists can be credited with having established a forum where national and international, historical, political, and cultural interests of our discipline can be presented and discussed. The objective is to promote and facilitate the understanding of the various problems specific to each nation as well as to support each other's point of view and strengthen the identity of psychiatry and its representatives in times of continuously changing ideologies.

\section{Historical and political spectres}

A psychiatric work would be incomplete without an evocation of the historical background. In this respect it is of interest to consider the various notions on physicians' obligations - their contradictory interpretations - and evoke the political role psychiatry plays in mental health politics. When we deal with the politics and history of European and particularly German psychiatry, a dark and terrifying past emerges. As psychiatrists, we should remember the mentally ill and the handicapped entrusted to us and who were murdered during the Nazi regime, because they were considered to be "life unworthy of life". Some 100000 to 200000 mentally ill and handicapped persons were exterminated due to the Nazification of German physicians, a fact which will overshadow German psychiatry forever and which should never be forgotten. Events such as these should stand out as warning signs for times when political ideologies rule supreme. At the same time, they command repeated and self-renewing debate and reflection on the ethical and moral standards of the medical profession, thus preventing physicians from ever becoming political tools again (Heimann, 1989).

We should also remember that our Soviet colleagues admitted one year ago in Athens that political conditions in the USSR have brought about abuse in psychiatric care. The fact that the USSR used psychiatric medicine as a means of political oppression was first brought to the attention of the Royal College in England. Inves- 
tigations are still assessing the extent of these practices. We should not forget our Soviet colleagues Bukowski and Glutzmann, imprisoned after criticizing the Soviet government for misusing psychiatry and who "became the martyrs of a factual, independent and scientifically founded psychiatry"' (Bayer, 1976).

A psychiatry solely based on scientific evidence was, is, and always will be endangered by multiple factors, even without the intervention of criminal or political abuse strategies as exemplified by its turbulent history, particularly during the early 19th century, when psychiatry became a discipline in its own right and adopted Griesinger's rigid scientific standards. Another example might be the introduction of the socalled "humane" treatment of the mentally ill some 200 years ago by Pinel (1793) who advocated that they be unchained. "Humane treatment" also led its advocates to build mental hospitals in the countryside so that patients could convalesce in peaceful and beautiful surroundings. On the other hand, the construction of university psychiatric hospitals evolving out of the former city asylums has received both positive and negative public response.

Until the end of World War II, psychiatry was forced to grovel at the outskirts of classical medicine. The Nazis used psychiatry's marginality to develop extermination plans for the mentally ill in relative secrecy and our discipline did not receive public attention until after the war. However, some time still had to elapse before the mentally ill obtained treatment which could qualify as humane. I personally believe that our society's increasing prosperity largely favored a more humane treatment of the mentally ill. That psychiatry did not receive much public attention between World War I and II can be attributed to economical depression. Moreover, anyone determined to enter the field of psychiatry ran the risk of being branded as somewhat deranged himself. Such was the state of the art when I began my studies in 1948. Since then, public opinion towards psychiatry has evolved considerably, particularly in Europe. As a result, negative as well as positive events in this field became a matter of public interest and subject to public debate.

\section{The achievements of applied psychiatry}

Let me start with the positive developments in psychiatry, which mainly concern applied psy- chiatry. When neuroleptics were introduced and gradually replaced "insulin treatment" and psychosurgery, the fate of the acute mentally ill, especially of schizophrenics, changed dramatically: closed wards in psychiatric hospitals were re-opened, outpatient treatment was extended to include severely disturbed schizophrenic patients, more intensive rehabilitation methods were implemented and individually designed treatment programs became available to outpatients. Today, we take these services for granted. Many depressive symptoms are now treated on an outpatient basis and the administration of lithium and carbamazepine has assisted many patients suffering from monopolar or bipolar depression in returning to relatively normal lives.

Equally positive results were obtained in applied psychotherapy which has been adapted to fit the needs of psychiatric patients. The psychoanalytical approach, based originally on an in-depth analysis of patient biography and the re-emergence of stressful situations reinforced the psychotic patient's vulnerability and triggered psychotic episodes. It has now been supplemented with more sensible psychotherapeutic methods.

Not only have psychiatric hospitals and state hospitals been modernized but physicians, psychologists, social workers and nurses have participated in special training programs which have improved treatment practices for the mentally ill and provided assistance for their families. As the 20 th century is drawing to a close, we can assert that the support and medical care for the mentally ill has adjusted to the needs of its patients and is proceeding in the right direction. The support and care concept is based on WHO guidelines and includes programs for treating addicts, especially alcoholics, as well as counselling services for persons with psychosomatic and psychogenic disorders. Unfortunately, these programs are not available everywhere.

\section{Standardized classification: pros and cons}

Positive results have also been observed in the diagnosis of psychopathological disorders due to the combined efforts of many individuals over the last two decades. Psychiatric diagnosis has thrown off the shackles of theory-laden concepts; for example, it no longer adheres to the narrow definition of illness advocated by Kraepelin. Although Kraepelin himself elaborated his theory at the end of his career, the initial concep- 
tual formulation is still present in today's psychiatric thinking. Due to its pragmatic approach, we now have an international consensus based on criteria that serve as guidelines for the entire profession. The diagnostic tools consist of simple symptom checklists, structured as well as standardized interviews, and questionnaires which I will not discuss here. Operational concepts validated with large samples allow us to draw a personality profile of each patient within a multidimensional setting and to classify patients' disorders according to ICD-10 or DSM-III-R standards.

In addition, the development of an objective language, describing specific behavior has been accepted by most psychiatric schools and improved international classification considerably. Not only have these classifications become the fundaments of epidemiological studies but they now serve as indispensible psychiatric tools. Prospective studies attain their empirical validation with these instruments and the objectives of therapy studies are elucidated because differentiated interpretations have now become possible on a clinical-psychopathological level.

This important sector of clinical psychiatry, the descriptive classification of mental illness obviously has its limits. Classification procedures can inhibit progress when they develop a momentum of their own which in turn prevents adequate use of these descriptive instruments. Their adequacy for research and practice is continuously being questioned because of too many rapid changes, a problem enhanced by the use of polydiagnostic procedures. This state of affairs seems to reflect the opposition to this approach and earlier nosological thinking whose etiological foundation was rather doubtful. Here, realistic conceptual biases have been replaced by nominalistic conventions. These nominalistic conventions change so rapidly that external validations are no longer possible. However, the major problem of clinical psychiatry lies in the vast number of questions left unanswered. In the past and particularly during this century, psychiatric research has succeeded in filling some of the gaps and gaining importance within the discipline and for public welfare.

\section{The impact of neighboring disciplines}

Psychiatry as a scientific discipline relies on two elements: the collection, analysis and reporting of medical investigations over the years, which actually constitute the very essence of psychiatry. The second element comprises impulses, results and techniques from neighboring disciplines. These influences are paramount for necessary advances in psychiatry but at the same time they can also lead to tunnel vision in that they promote causal thinking, ie positing simple explanations for unknown causes of mental disorders.

Theodor Meynert's Clinical Lectures on Psychiatry Founded on Scientific Premises, published in 1890, illustrates this point. These lectures contain numerous clinical case studies which describe well-known mental disorders quite well. The "scientific foundations" were, however, nothing more than attempts to explain disorders in terms of available knowledge of the brain and its anatomy and physiology, notions at that time psychiatrists were already familar with. For instance, Theodor Meynert writes: "Psychiatry is also slowly turning into an explanatory science with the broadening and sophistication of our knowledge on the anatomical structures (of the brain) and their functions".

Kraepelin called this type of writing and thinking "brain mythology": today, we would agree with him.

The reduction of mental disorders to a mere expression of brain dysfunction - following Griesingers' postulate that "mental disorders are brain disorders" - has fascinated psychiatrists repeatedly. However, Griesinger's remark was not directed at the so-called romantic supporters of the "psychotype", but against the German psychiatrists promoting the "somatotype", who wanted to establish a causal relation between mental disorders and physiological dysfunctions not restricted to the brain.

Ever since their inception in the fifties, psychotropic drugs and their effects on psychotic, depressive, and anxiety disorders have been heavily debated. Their importance within psychiatry has nonetheless grown steadily. Although no pathogenic relationships between cerebral functions and mental disorders have been clearly established despite tremendous research efforts, the "biological" approach currently rules psychiatric investigation. The fascination with this biological paradigm seems justified, particularly when one considers all the perspectives offered by the computerized techniques now used in brain research. Today we can observe how a living brain functions and is equipped with observational material our ancestors never even dreamed of. 


\section{Neurobiology and receptor research}

Should psychiatry become a subdiscipline of neurology? The question has been raised since considerable progress has been made in the field of neurobiology and particularly in receptor research. However, when reviewing recent findings in this area, the clinician will quickly realize that these do not reveal much relevant or clearcut evidence at a psychological level, since the subject matter is far too complex.

Amytriptiline, one of the most effective antidepressives on the market, affects many disparate receptor systems and thus belongs to the so-called "dirty drugs". Hopes for a better outcome with the newly discovered chemical substances thought to have an effect only on monoaminergic or serotonergic structures had to be largely abandoned. We therefore have to accept that important therapeutic breakthroughs in psychopharmacology are based on careful empirical evidence, the explanations of which are controversial. This applies to the dopamine hypothesis which attempts to explain schizophrenia on the basis of neuroleptic effects, as well as those hypotheses interpreting depressive and manic states. Another example is the dexamethasone suppression test used in neuroendocrinology where systematic investigations disproved the specificity of endogenous depression.

Hypercortisolemia in depressive syndromes and anorexia nervosa can just as well be the result of stress produced by the psychological disorder itself. This interpretation is more convincing than that of a pathophysiological cause of one or several psychopathological processes.

We clearly have to get used to the fact that the conditions biological psychiatric research investigates are so complicated that we should not expect simple explanations from new approaches. This also applies to psychophysiology, as exemplified by the inhibitory mechanism of the orienting response and even more by the electrophysiological brain functions which correspond to the disturbed information-processing during psychotic states. Neither has chronobiological research been able to shed more light on pathophysiological depressive states. Since disparate investigatory methods are used in these studies due to the large amount of variables, the results obtained for chronobiological rhythm disorders were highly discrepant. Thus, biological psychiatry is pursuing the quest for knowledge and tries to find biological mechanisms underlying mental disorders.

\section{Psychoanalytical and behavioral therapy}

In today's research, psychoanalytical explanations for mental disorders have receded into the background. The psychoanalysis of biographical data has led to a better understanding of developmental psychodynamic processes which were considered to manifest themselves in decompensatory processes during psychoses and/or produce neurotic symptoms. Psychoanalysis as practiced by Freud developed out of the life history of highly neurotic individuals, and in my opinion has already passed its zenith. Todate, it has been displaced by cognitive behavioral therapy, Rössler (1986) characterized the relationship between the two therapeutic approaches as follows: "One method explains an awful lot but its results are poor, while the other method has excellent results but hardly explains anything". For an effective and humane psychiatric treatment, both approaches are important, and it would be expedient to supplement one approach with the other. A patient's life history is the prerequisite for understanding his psychological disorders. Psychotherapeutic treatment of stressful situations also requires that the patient learns specific coping strategies enabling him to interact with his environment in spite of his handicaps and vulnerabilities. This means using the behavioral approach. Both approaches must be confined in order to effectively supplement biological treatment methods.

\section{Social interactions}

Yet another angle to consider are social factors, which can trigger or sustain mental disorders. Recently, psychiatric research has largely focussed on the variable "high expressed emotion" in terms of the interaction between the patient and his immediate family. Various training programs have been designed to promote the social skills of all persons concerned. Most theoretical approaches in this area are systemic in nature.

\section{Psychiatry today}

Specific to psychiatry is the fact that the abovementioned explanatory approaches of mental disorders have always led and can still lead to a dead-end, although many psychiatrists now use the multitherapeutic approach. In this context we 
should remember the anti-psychiatry movement in the seventies which endeavoured to do away with the term "mental illness", considered as a nosological label given to individuals by the psychiatric establishment. As opposed to this, the trend today is to overstress the weight of neurobiological findings. Then again, psychiatric practitioners still insist that only an in-depth psychoanalysis can treat neurosis, depression or schizophrenia.

Today's diagnostic methods are founded on the observation of individual behavior in Ludwig Binswanger's words (1922) "Not only the "brain" or the "soul" presents itself for examination to the psychiatrist, but a "person". Binswanger conceded that detours via cerebral functions and psychic organism were necessary insofar, I would add, as they are assessable with psychobiological models. They are necessary in order to justify the delimitation of personal freedom, to elucidate the effects of psychiatric syndromes on behavior and to promote positive patient development. Using the theories of Freud's and Wernicke's, Binswanger (1955) demonstrated that psychiatry can only make limited use of converging theories because of the impossibility to explain mental disorders on the grounds of cerebral processes or personal experience alone. Communication, systemic and social theories may contribute to the understanding of mental illness, but neither of these is elaborated enough to produce a satisfactory and exclusive explanation.

Seymore Kety (1982), one of the greatest neurobiologists of our times, came to a similar conclusion when he asserted, describing psychiatry's dependence on other neuro-sciences, that there was a lot more to the brain than vascular circulation and a lot more to psychiatry than the brain. $\mathrm{He}$ added that the first priority for psychiatry, in order to satisfy expectations, was to accept that human behavior was determined by many factors. The decisions which determine our behavior do not reflect inborn disposition and brain chemistry cannot explain divergences between individuals no matter how long we investigate it because the majority originate elsewhere. Kety demonstrated that linguistic symbols can only be explained and understood with the help of phenomenology and human experience which gave them life in the first place. Kety is, I believe, a shining example to other scientists in that he dedicated his life to research of the brain without ever forgetting or neglecting the human being behind the psychophysiological organism.

\section{Theories}

By citing Binswanger and Kety, the former oriented towards philosophical existentialism and the latter an empirically working neurobiologist, I wanted to demonstrate that the psychiatric identity does not tolerate either theoretical or practical narrow-mindedness. Psychiatry is a dynamic scientific and medical discipline and in order to remain that way, it has to cooperate with the social sciences on an interdisciplinary level utilizing and integrating their findings on mental disorders into its therapeutic concept.

For the practitioner in psychiatry, this means dependence on advances made in various research areas and selection of the material relevant to the individual case and the elaboration of an optimal therapy plan. The treatment of psychiatric patients demands a continuous review of the different aspects of mental illness as well as the identification of the patients' actual needs, an ability sometimes called a physician's "special touch". This "touch" can only be acquired through experience and only be mediated to those who are actively involved in patient care.

\section{Psychobiology's intricacy}

What can we expect from "hard" science? The natural sciences and modern technology are conceptualized as deterministic systems which are both linear and causal in nature. Today we are faced with highly complex systems that take us to the very limits of linear causal thinking. For example, our assumption about the properties of these complex systems as we imagine them when treating patients tends to be causally oriented only within certain limits. The non-linearity of many feedback processes only allows us to make probability statements about prognosis and therapeutic outcome. Moreover, psychobiological organisms are characterized through discontinuities, ie precipitous changes occuring at a certain point in time or changes of unknown etiology. At the end of the 20th century our understanding of biological processes and particularly psychobiological models, is radically altered. What we miss are the tools required to apply the models in a sensible manner. I believe nevertheless that it would be premature to abandon confirmed research strategies at this time, as the way into the virgin territory of non-linearity still has to be built by psychiatric medicine.

Insight into the complex psychobiological 
organization of human beings should make us more humble with respect to our demands for explanations and more cautious when interpreting empirical findings. Acceptation of the limitations of our scientific models in terms of a methodological consciousness as advanced by Jaspers will characterize European psychiatry in the future.

\section{References}

Bayer V (1976) Psychiatrie im Dienste politischer Ideologie. In: Standorte der Psychiatrie. Zum Selbstverständnis einer angefochtenen Wissenschaft
(Hippius H, Lauter H, eds) Urban und Schwarzenberg, Munich, 131-144

Binswanger L (1922) Einführung in die Probleme der Klinischen Psychologie. Springer, Berlin, 1-2

Binswanger L (1955) Freud und die Verfassung der klinischen Psychiatrie. Ausgewählte Vorträge und Aufsätze. Francke, Berne, vol 2

Heimann H (1989) Der psychiatrische Patient im Nationalsozialismus und heute. Fundam Psychiatr 3, 198-202

Kety S (1982) Psychiatrists on Psychiatry (Shepherd $\mathrm{M}$, ed) Cambridge University Press

Meynert T (1890) Klinische Vorlesungen über Psychiatrie auf wissenschaftlicher Grundlage. Wilhelm Braunmüller, Vienna

Rössler D (1966) Das Verhältnis der Psychiatrie zu ihren Nachbardisziplinen (Heimann H, Gaertner $\mathrm{HJ}$, eds) Springer, Berlin, 116 